\title{
Brief Report: Search for DNA Markers in Two Autistic Males with the Fragile $X$ Syndrome ${ }^{1}$,
}

\author{
Luke Y. Tsai \\ Department of Psychiatry, University of Michigan \\ Raymond R. Crowe \\ Department of Psychiatry, University of Iowa College of Medicine \\ Shivanand R. Patil and Jeff Murray \\ Department of Pediatrics, University of Iowa College of Medicine \\ Janice Quinn \\ Department of Psychiatry, University of Iowa College of Medicine
}

Kanner (1943) was the first investigator in the field of infantile autism to suggest a genetic predisposition in children who later developed the symptoms of autism. Family and twin studies of autism have shown that autism is occasionally aggregated in families (reviewed by Folstein \& Rutter, 1987). These kinds of studies, however, tell us little about the nature of the genetic defect or defects. A number of recent studies have reported an increased prevalence of the fragile $\mathbf{X}$ chromosome in autistic populations. A recent review summarized the results of 10 studies of a total of 594 autistic males and arrived at a mean rate of $8.4 \%$ of autistic males having the fragile site (Bregman, Dykins, Watson, Ort, \& Leckman, 1987). The meaning of this association is not clear. However, it has been suggested that when a chromosomal abnormality is associated with a disease, a gene causing the disease may be located within the region of the abnormality. Thus, the association does suggest a discrete region of the genome in which to search

'We acknowledge the following investigators who allowed us to use their probes: Richard Lawn (Factor VIII), Thomas Caskey (HPT), Lucio Luzzatto (G6PD), J. L. Mandel (St-14.1), and Kay Davies (MN12). 
for a genetic defect in autistic males. Furthermore, a recent study using DNA probes has found genetic alterations (i.e., deletions) in Lesch-Nyhan syndrome (Yang, Patel, Chinault, Stout, Jackson, Hildebrand, \& Caskey, 1984), an X-linked disease with considerable overlapping symptoms with autism. For the present study, we reasoned that the most productive region to search for submicroscopic structural abnormalities (i.e., deletions) would be in the Xq26-q28 region because the fragile site has been mapped to Xq27.3. Of course, it is also possible that genetic alterations that contributed to the autistic syndrome would be found in other regions or chromosomes. A number of DNA probes in the Xq26-q28 region have been developed, and this paper reports the use of six of these to study the $X$ chromosome of two boys (ages 13 and 17, respectively) with both autism and the fragile $X$ chromosome.

The 2 patients were identified through a study of $\mathrm{X}$ chromosome abnormalities in autistic boys in which 20 subjects were karyotyped, and 2 , the subjects of these case reports, were found to have a fragile $\mathrm{X}$ site. Patient $A$ was originally evaluated at age 3 years 9 months, and Patient $B$ at age 8 years 8 months by the Iowa Autism Program. Initial evaluation included physical and neurological examinations, EEG, and amino acid screen. None of these evaluations revealed an organic cause for their behavioral and cognitive problems. The Cattell Infant Intelligence Scale was administered to Patient $\mathbf{A}$, and the Stanford-Binet Intelligence Scale to Patient B. Patient A's IQ was in the range of 30-35, and Patient B had an IQ of 56. The initial clinical evaluation noted that they satisfied Kanner's (1943) criteria for infantile autism. Their records were reviewed for the present study by one of us (L.Y.T.), and both the patients satisfied DSM-III criteria (American Psychiatric Association, 1980) for Pervasive Developmental Disorder-Infantile Autism. When they participated in the present study, they were attending autism classrooms for trainable students in local public schools.

Lymphocyte cultures from the patients' blood were set up in medium TC 199 with $5 \%$ fetal calf serum according to the procedure of Sutherland (1979). The cells were processed for chromosome analysis after 96 hours of culturing.

A folic acid fragile site at Xq27 was confirmed by two independent karyotypes (in both Patients A and B). We examined the Xq26-q28 region using six DNA probes, comparing the patients with the remaining 18 autistic subjects without fragile sites and three normal controls. The six probes and their locations were two Factor VIII probes (625.1 and 625.8; Xq28) (Gitschier et al., 1984), glucose-6-phosphate dehydrogenase (G6PD; Xq28) (Toniolo et al., 1984), hypoxanthine phosphoribosyl transferase (HPRT: Xq26-q27.3) (Brennand, Konecki, \& Caskey, 1983), and two anonymous probes DXS52 (ST 14.1) (Xq28) (Oberle, Brayna, Camerino, White, \& Man- 


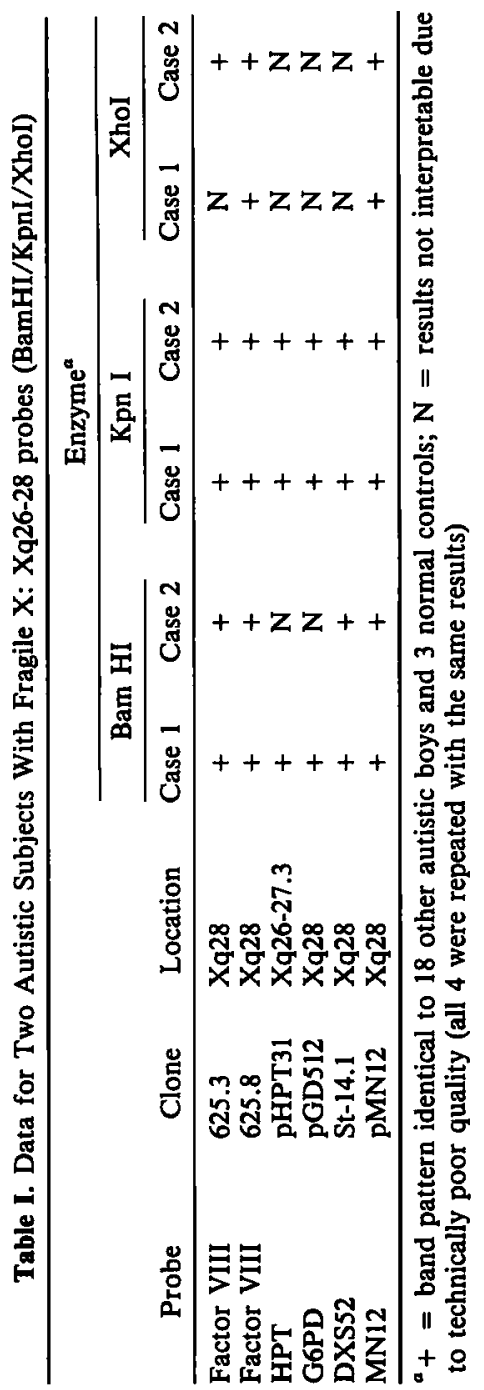


del, 1985) and MN12 (Xq28) (Patterson et al. 1987). These probes flank the fragile site at $\mathrm{Xq27.3.}$

Genomic DNA was extracted from buffy coat preparations using the phenol/chloroform extraction procedure and digested with three restriction enzymes, according to specifications recommended by the supplier (BRL); XhoI, KpnI, and BamHI. The rationale for the choice of enzymes was to produce large fragment sizes in order to maximize the probability that a deletion, if present, would overlap one of the fragments. The DNA was electrophoresed on $15 \times 30 \mathrm{~cm}, 0.4 \%$ agarose gels at $40 \mathrm{~mA}$ for 72 hours, transferred to Zetabind membranes by Southern blotting, and hybridized with the probes labeled with P32dCTP by the random primer method. The blots were given three 5-minute, room temperature, low-stringency (2 X SSC) washes, followed by three 10 -minute, $55 \mathrm{C}$, high-stringency $(0.1 \times \mathrm{XSC})$ washes, and autoradiographed for 48 hours at $-80 \mathrm{C}$ with Kodak XAR-5 film and Cronex image intensifier screens.

The results are summarized in Table I. A plus sign indicates that the patients had the same pattern of bands as the comparison subjects, and $\mathrm{N}$ indicates that the autoradiograph was not interpretable for technical reasons. Whenever an autoradiograph was uninterpretable, it was repeated, and if an interpretable autoradiograph was not obtained on the second attempt, it was scored as $\mathbf{N}$. Interpretable results were obtained for each probe with at least one enzyme and no evidence of a deletion (missing or displaced bands) was found.

Although it appears that from this study so far there are no clinically useful markers for autism, it should be pointed out that the mother and the brother of Patient A were negative for fragile X chromosome. (Mother and siblings of patient $B$ have not been tested yet for fragile X.) More families, particularly those with multiple incidence of fragile $X$ syndrome, should be studied. Furthermore, in the present study, only six probes were used. With the availability of a growing number of probes to the Xq26-q28 region in future investigations one can be confident that if deletions are present, they would be detected.

\section{REFERENCES}

American Psychiatric Association. (1980). Diagnostic and statistical manual of mental disorders (3rd ed. pp. 87-90). Washington, DC: Author.

Bregman, J. D., Dykens, E., Watson, M., Ort, S. I., \& Leckman, J. F. (1987). Fragile-X syndrome: Variability of phenotypic expression. Journal of the American Academy of Child and Adolescent Psychiatry, 26, 463-471.

Brennand, J., Konecki, D. S., \& Caskey, C. T. (1983). Expression of human and Chinese hamster hypoanthine-guanine phosphoribosyltransferase cDNA recombinants in cultured LeschNylan and Chinese hamster fibroblast. Journal of Biological Chemistry, 16, 9593-9596. 
Folstein, S. E., \& Rutter, M. L. (1987). Autism: Familial aggression and genetic implications. In E. Schopler \& G. B. Mesibov (Eds.), Neurobiological issues in autism (pp. 83-105). New York: Plenum Press.

Gitschier, J., Wood, W., Goralka, T., Wion, K., Chen, E., Eaton D., Vehar, G., Capon, D., \& Lawn, R. M. (1984). Characterization of the human factor XIII gene. Nature, 312, 326-330.

Kanner, L. (1943). Autistic disturbances of affective contact. Nervous Child, 2, 217-250.

Oberle, I., Brayna, D., Camerino, G., White, R., \& Mandel, G. J. (1985). The telomeric region of the human $\mathrm{X}$ chromosome long arm: Presence of a highly polymorphic DNA marker and analysis of recombination frequency. Proceedings of the National Academy of Sciences (USA), 82, 2824-2828.

Patterson, M., Kenwrick, S., Thibodeau, S., Faulk, K., Mattei, M. G., Mattei, J. F., \& Davies, K. E. (1987). Mapping of DNA markers close to the fragile site on the human X chromosome at Xq27.3. Nuclear Acid Research, 15, 2639-2651.

Sutherland, G. R. (1979). Heritable fragile sites on human chromosomes. I. Factors affecting expression in lymphocyte cultures. American Journal of Human Genetics, 31, 125-135.

Toniolo, D., D’Urso, M., Martini, G., Persico, M., Tufano, V., Battistuzzi, B., \& Luzzato, L. (1984). Specific methylation pattern at the 3' end of the human housekeeping gene for glucose-6-phosphate dehydrogenase. EMBO Journal, 3, 1987-1997.

Yang, T. P., Patel, P. I., Chinault, A. C., Stout, J. T., Jackson, L. G., Hildebrand, B. M., \& Caskey, C. T. (1984). Molecular evidence for new mutation at the "hprt" locus in LeschNyhan patients. Nature, 310, 412-414. 